\title{
Efficient Transduction with Recombinant Adenovirus in EBV-transformed B Lymphoblastoid Cell Lines
}

\author{
Hye-Jin Kim, Hyun-Il Cho, Yoon-Hee Han, Soo-Young Park, Dong-Wook Kim ${ }^{\dagger}$, Dong-Gun Lee ${ }^{\dagger}$, Jee-Hoon Kim, \\ Wan-Shik Shin ${ }^{\dagger}$, Soon-Young Paik, Chun-Choo Kim ${ }^{\dagger}$, Young-Seon Hong ${ }^{\dagger}$ and Tai-Gyu Kim* \\ Department of Microbiology and Immunology, Clinical Institute of St. Mary's Hospital \\ 'Department of Internal Medicine, College of Medicine, The Catholic University of Korea, Seoul 131-701, Korea
}

Received 6 August 2003, Accepted 20 August 2003

\begin{abstract}
The Epstein-Barr-transformed B lymphoblastoid cell lines, LCL, which express antigens, are potential antigenpresenting cells (APCs) for the induction of cytotoxic $\mathbf{T}$ lymphocytes in vitro. However, transfecting LCL with subsequent selection by antibiotics is notoriously difficult because the plating efficiencies of LCL are reported to be $1 \%$ or less. Therefore, this study investigated the optimal conditions for increasing the transduction efficiency of a recombinant adenovirus to $L C L$ for use as a source of APCs. The transduction efficiencies were $<13 \%$ (SD \pm 2.13) at a multiplicity of infection (MOI) of 100, while it was increased to $28 \%(\mathrm{SD} \pm 9.43)$ at an MOI of 1000 . Moreover, its efficiencies to $\mathrm{LCL}$ that expressed the coxsackie adenovirus receptor were increased to $60 \%$ (SD \pm 6.35 ) at an MOI of 1000 , and were further increased to $70 \%$ (SD \pm 4.56 ) when combined with the centrifugal method. The cationic liposome or anionic polymer had no effect on the transduction efficiency when compared to that of the centrifugal method. These results may be used as a convenient source of target cells for a CTL assay and/ or autologous APCs for the induction of the in vitro CTL responses that are specific to viral and tumor antigens.
\end{abstract}

Keywords: Adenovirus, Centrifuge, Coxsackievirus and adenovirus receptor, EBV-transformed B lymphoblastoid cell lines, Gene transfer
*To whom correspondence should be addressed. Tel: 82-2-590-1216; Fax: 82-2-594-7355

E-mail: kimtg@cmc.cuk.ac.kr

\section{Introduction}

The Epstein-Barr virus (EBV) is a potent inducer of polyclonal B lymphocyte proliferation and is a tool for establishing human B lymphoblastoid cell lines (LCL) (George et al., 1972; Bill and Willie, 1977; Hureley and Thorley-Lawson, 1988). In studies on the human immune system, LCL lines were convenient sources of antibodyproducing cells and antigen-presenting cells since they can be readily established from each individual. Moreover, LCL lines frequently express high constitutive levels of the major histocompatibility complex (MHC) class I and class II antigens (Dustin et al., 1988; Ohlen et al., 1989), as well as high constitutive levels of the molecules that are involved in the second signals that are required for $\mathrm{T}$ cell activation, such as B7 molecules (Mueller et al., 1989). These obvious advantages of the LCL lines are counteracted to some extent by the poor tissue culture performance, which results mainly in poor cloning efficiency (Nissol and Ponten, 1975; Richter et al., 1990). Therefore, the transfection of the LCL lines with the subsequent selection by antibiotics is notoriously difficult because the plating efficiencies of the LCL lines have been reported to be $1 \%$ or less.

In the classic model of an antigen presentation to cytotoxic $\mathrm{T}$ lymphocytes (CTLs), foreign antigens must be synthesized in the cytoplasm of the infected cell and be processed by a cellular protease. In order to examine the CTL response to the individual viral antigens, it is usually necessary to express the viral gene of interest within the target cell itself. Among a number of vectors, the recombinant adenovirus (rAdV) has the fundamental quality of being able to provide efficient in vivo and in vitro gene transfer to both dividing and quiescent cells. The rAdV can be produced at high titers, which is essential for their experimental and clinical use. However, an efficient $\mathrm{rAdV}$ infection requires the presence of the coxackie adenovirus receptor (CAR) for the virus to attach to the cell surface and of an integrin $\alpha_{v} \beta_{3}$ or $\alpha_{v} \beta_{5}$, which promotes virus 
internalization (Huang et al., 1995; Bergelson et al., 1997). However, LCL lines are not susceptible to rAdV infection because of the inefficient binding to the cell surface and internalization (DeMatteo et al., 1997; Leon et al., 1998). In order to improve the efficiencies of rAdV infection, a number of methods were used. These methods include the rAdV complex with the lipids or polycations (Byk et al., 1998; Clark et al., 1999; Lanuti et al., 1999) and a centrifugal transduction method, which has been used for many years to enhance the viral infection to cells, such as the cytomegalovirus (Hudson, 1988) and retrovirus (Ho et al., 1993; Bahnson et al., 1995).

This study compared the transduction efficiencies of rAdV under various conditions for its ability to generate genemodified LCL lines. This approach provides a useful strategy for analyzing the human $\mathrm{T}$ cell response to viruses and tumors and for the generation of the antigen-specific CTLs for adoptive immunotherapy.

\section{Materials and Methods}

Cell lines The human adenovirus 5-transformed human embryonic kidney 293 (HEK 293; CRL-1573) and the amphotropic packaging cell line BING (CRL-11554) were purchased from the American Type Culture Collection (ATCC; Rockville, USA). All of the cell lines were cultured in Dulbecco's modified Eagle medium (DMEM; GibcoBRL, Grand Island, USA) that was supplemented with $10 \%$ fetal bovine serum (FBS), $2 \mathrm{mM} \mathrm{L}$-glutamine, $100 \mathrm{U} / \mathrm{ml}$ penicillin, and $100 \mu \mathrm{g} / \mathrm{ml}$ streptomycin (GibcoBRL). The anti-CAR monoclonal antibodies (MAb) that produced the hybridoma cell line RmcB (CRL-2379) and B95-8 (VR-1492), which is a marmoset $\mathrm{B}$ cell line transformed by the human type $1 \mathrm{EBV}$, was also purchased from ATCC. They were maintained in RPMI-1640 (GibcoBRL) with $15 \%$ FBS, $2 \mathrm{mM}$ L-glutamine, $100 \mathrm{U} / \mathrm{ml}$ penicillin, and $100 \mu \mathrm{g} / \mathrm{ml}$ streptomycin.

Generation of EBV-transformed B-lymphoblastoid cell line The LCL lines were established by transforming the B-cells from the peripheral blood mononuclear cells (PBMC) of laboratory volunteers. The mononuclear cell fraction was isolated by a FicollHypaque density gradient. After washing twice, the freshly isolated PBMC were plated at $2 \times 10^{6}$ cells per well in flat-bottomed $24-$ well plates in the supplemented RPMI-1640 medium and $1 \mu \mathrm{g} / \mathrm{ml}$ cyclosporin A, with $1 \mathrm{ml}$ of the supernatant derived from B95-8 cultures. Once the B95-8-infected LCL lines were established, they were expended into a $75 \mathrm{~cm}^{2}$ flask for a long-time culture. The aliquots were then frozen.

Production and titration of recombinant retrovirus encoding CAR The CAR gene was amplified from the HeLa cell line by a polymerase chain reaction (PCR) using the CAR sense primer, 5'CGTAGAATTCCATGGCGCTCCTGCTGTG-3', and the CAR anti-sense primer, 5'-TACTGCTCGAGCTATTTACGACAGCAA AAG-3' (Kim et al., 2002). The PCR products were cloned into the recombinant viral vector pLXSN (Clontech, Palo Alto, USA) containing EcoRI and XhoI, and sequenced to determine the possible Taq polymerase errors. The plasmid that encoded the proviral constructs was introduced into the BING producer cell line using a commercially available kit for Calcium-Phosphate transfection (Invitrogen, San Diego, USA) (Lee et al., 2001). After $48 \mathrm{~h}$, the recombinant retroviruses were harvested and titrated on NIH3T3 cells, which were then used for the transduction experiments. The virus titer was $1 \times 10^{6} \mathrm{PFU} / \mathrm{ml}$.

Transduction and establishment of stable CAR-expressing LCL The LCL lines were transduced by incubation on a 24-well culture plate at a concentration of $1 \times 10^{6} \mathrm{cells} / \mathrm{ml}$ with the CAR-encoding recombinant retroviral supernatant diluted $1: 1$ in a culture-medium containing $8 \mu \mathrm{g} / \mathrm{ml}$ polybrene (Sigma, St. Louis, USA) for $4 \mathrm{~h}$. The medium was removed after incubation and replaced with a fresh normal medium. This procedure was carried out at 0,1 , and $3 \mathrm{~d}$. Subsequently, the cells were grown in a culture medium containing $0.8 \mathrm{mg} / \mathrm{ml}$ of G418 (Invitrogen). The LCL lines were selected, based on their neomycin-resistance, for $10-14 \mathrm{~d}$ in a selective medium. They were maintained in a culture medium containing 0.5 $\mathrm{mg} / \mathrm{ml}$ of G418. The bulk cultures of the neomycin-resistance cells were used without further selection. The LCL lines, transduced with retrovirus encoding CAR, are referred to as LCL/CAR.

Flow cytometric analysis for CAR expression In order to determine the CAR expression level, the cells were labeled with antiCAR mAb (clone; T84.66A3.1A.1F2) for $45 \mathrm{~min}$ on ice. They were then incubated with fluorescein isothiocyanate (FITC)-conjugated secondary goat anti-mouse IgG antibodies (Cappel, Aurora, USA) for $30 \mathrm{~min}$ on ice. Next, the cells were assayed by FACS Calibur flow cytometry (Becton Dickinson, Franklin Lakes, USA).

Production of recombinant adenovirus encoding GFP The replication-defective rAdV encoding green fluorescent protein (GFP; rAdVGFP) was obtained from Qbiogene (Qbiogene, Carlsbad, USA) and amplified in HEK293 cells. The rAdVGFP were purified from the cell lysates by banding twice in $\mathrm{CsCl}$ density gradients, as described previously (Eloit et al., 1990). The viral products were desalted and stored at $-80^{\circ} \mathrm{C}$ in phosphate-buffered saline (PBS) containing $10 \%$ glycerol $(\mathrm{v} / \mathrm{v})$. The viral stock titer was determined using the tissue culture infectious dose $\left(\mathrm{TCID}_{50}\right)$ method. The rAdVGFP titer that was used in this study was $1 \mathrm{X}$ $10^{12} \mathrm{PFU} / \mathrm{ml}$.

Transduction and analysis of GFP expression In order to determine the transduction efficiency, $2 \times 10^{5}$ LCL lines were suspended in Opti-MEM (GibcoBRL) and exposed to rAdVGFP at a multiplicity of infection (MOI), ranging from 50 to 1,000 for $4 \mathrm{~h}$ at $37^{\circ} \mathrm{C}$ in a $96-w e l l$ flat bottom plate, or they were centrifuged at the indicated gravity force for $2 \mathrm{~h}$ and incubated at $37^{\circ} \mathrm{C}$ for $2 \mathrm{~h}$. The cells were then added to a freshly-prepared RPMI 1640 medium containing 30\% FBS. After $2 \mathrm{~d}$ incubation, the GFP expression levels were analyzed by flow cytometry. For the complementation experiments, an anionic polymer [dextran sulfate $\left(M_{r} 500,000\right)$, a heparin sodium salt, protamine sulfate, polybrene (Sigma)] or polycationic lipid [lipofectamine (GibcoBRL), Superfect (Qiagen, Hilden, Germany)] were preincubated with rAdGFP and $2 \mu \mathrm{g} / \mathrm{ml}$ of the reagents for $30 \mathrm{~min}$, which were then added to the LCL lines for transduction. 
(A)

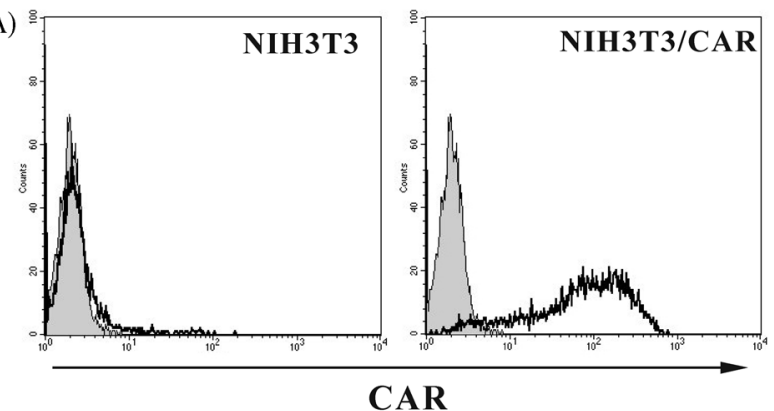

(B)

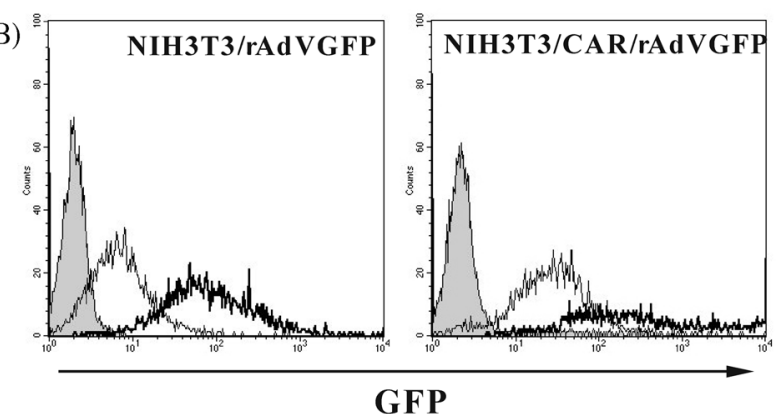

Fig. 1. Expression of the coxsackie adenovirus receptor (CAR; A) and green fluorescent protein (GFP; B) in the parental NIH3T3 and CAR-expressing NIH3T3 (NIH3T3/CAR) cell lines. (A) The isotype controls are shaded. Light line: The cells were incubated with anti-CAR mAb. (B) The isotype controls are shaded. Each cell line was transduced with rAdVGFP at an MOI of 100 (light line) and an MOI of 1000 (bold line). All of the data were ungated for the GFP positive cells.

\section{Results}

Transduction efficiency of rAdV in LCL lines expressing CAR In order to confirm the function of CAR, the transduction efficiency of rAdVGFP was initially evaluated in the NIH3T3 cells expressing CAR (NIH3T3/CAR). The NIH3T3 cell lines showed $>90 \%$ CAR expression after they were transduced with the recombinant retrovirus encoding CAR and selected with G418 (Fig. 1A). A flow cytometric analysis was performed $48 \mathrm{~h}$ after transduction with rAdVGFP (at MOIs of 100 to 1000) to determine the transduction efficiency of the AdV infection on the parental NIH3T3 and NIH3T3/CAR cells. At an MOI of 100, the rAdVGFP transduction rate to NIH3T3 was $24.5 \%$ while the rAdVGFP transduction rate to NIH3T3/CAR was $85.9 \%$. At an MOI of 1,000 , both of the cells showed a transduction efficiency of $>90 \%$, but the mean fluorescence intensity of the GFP expression in the NIH3T3/CAR was higher than in the parental cells (Fig. 1B).

In the case of the LCL lines, the CAR molecule was not expressed, and the CAR-expressing LCL lines (LCL/CAR) were generated through transducing them with a recombinant retrovirus encoding CAR (Fig. 2A). The CAR expression rate in the LCL lines was $>80 \%$ by flow cytometric analysis. Subsequently, the transduction efficiency of rAdVGFP was
(A)

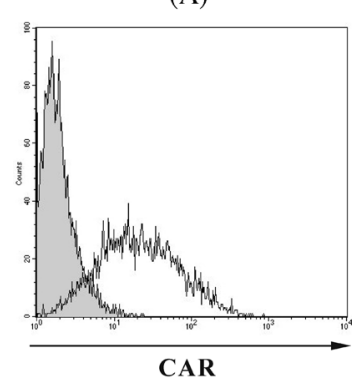

(B)

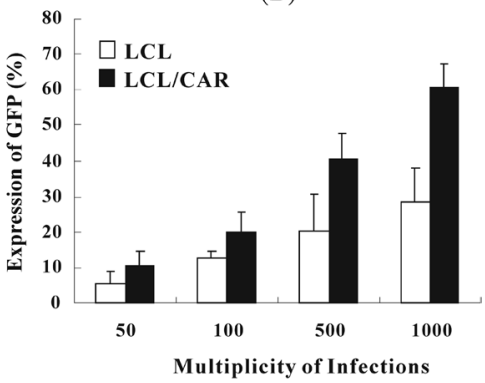

Fig. 2. Expression of the coxsackie adenovirus receptor (CAR; A) and green fluorescent protein (GFP; B) in parental LCL and CAR-expressing LCL (LCL/CAR) lines. (A) LCL/CAR lines were generated by transduction with the recombinant retrovirus encoding CAR and were selected with G418 for 2 wk. The isotype controls are shaded. Light line: The cells were incubated with anti-CAR mAb. One of five experiments with similar results is shown. (B) The paternal LCL (white bar) and LCL/CAR (black bar) lines were transduced with rAdVGFP at the indicated MOI for $4 \mathrm{~h}$ at $37^{\circ} \mathrm{C}$, then subsequently incubated for $2 \mathrm{~d}$. The GFP expression level was measured by flow cytometry. The results represent a mean \pm SD of five experiments.

investigated in the parental LCL and LCL/CAR lines at various MOIs. The AdV-mediated gene transfer, as well as its efficiency, increased in an MOI-dependent manner (Fig. 2B). At an MOI of 100, the average rate of rAdVGFP transduction to the parental LCL lines was $<13 \%$ (SD \pm 2.13 ) while the average rate of rAdVGFP transduction to the LCL/CAR lines was approximately $20 \%$ (SD \pm 5.81 ). Furthermore, at an MOI of 1000 , the average rate of the GFP expression in the parental LCL lines was approximately $28 \%$ (SD \pm 9.43 ). In the LCL/ CAR lines, the average rate of the GFP expression was $>60 \%$ $(\mathrm{SD} \pm 6.35)$. The rAdVGFP infection had no appreciable cytotoxic effect on the LCL lines.

Transduction efficiency of rAdV in LCL lines using centrifugation In order to verify the effect of centrifugal force to a rAdV infection in the LCL lines, this study primarily tested the transduction efficiencies at various rotor speeds at an MOI of 500. The rate of rAdVGFP infection and its efficiencies were enhanced by increasing the centrifugal force (Fig. 3A). Centrifugation had no effect on the cell viability. In further experiments, the LCL lines were tested at $2,000 \times g$ for $2 \mathrm{~h}$. Under this condition, the centrifugal transduction efficiency of the LCL lines was increased to $50 \%$ ( $\mathrm{SD} \pm 9.65)$, which is in contrast to a $28 \%$ ( $\mathrm{SD} \pm 9.43$ ) transduction efficiency without centrifuging the LCL lines at an MOI of 1000 (Fig. 3B). Moreover, this study examined whether or not liposomes and an anionic polymer could enhance the transduction efficiency of rAdV to the LCL lines. After preincubating them with the polycationic liposomes or anionic polymers, the rAdVGFP was transduced to the LCL lines by centrifugation at an MOI of 100 (Table. 1). The anionic polymer, dextran sulfate, and heparin showed 

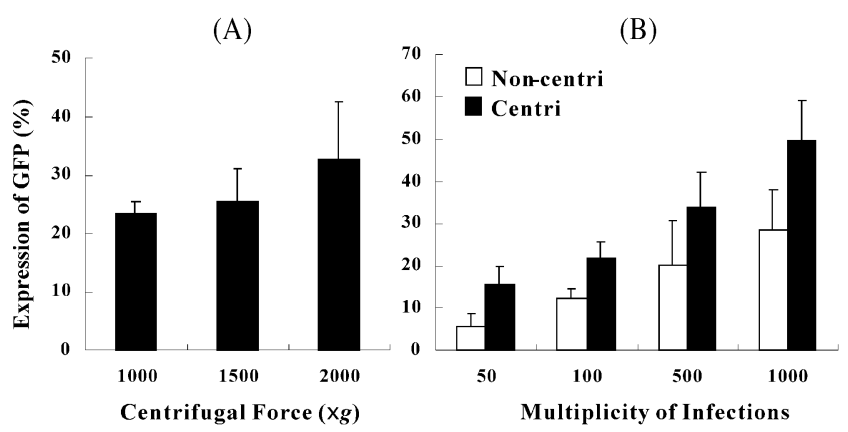

Fig. 3. Transduction efficiency of rAdVGFP on LCL lines at various centrifugal forces (A) and at various multiplicity of infections (MOIs) (B). (A) The LCL lines were transduced at the indicated centrifugal force with rAdVGFP at an MOI of 500, then subsequently incubated for $2 \mathrm{~d}$. The results represent a mean $\pm \mathrm{SD}$ of three experiments. (B) The LCL lines were transduced with rAdVGFP at the indicated MOI without centrifugation (white bar) or at $2,000 \times g$ for $2 \mathrm{~h}$ (black bar), which were then cultured for $2 \mathrm{~d}$. The green fluorescent protein (GFP) expression level was measured by flow cytometry. The results represent a mean \pm SD of five experiments.

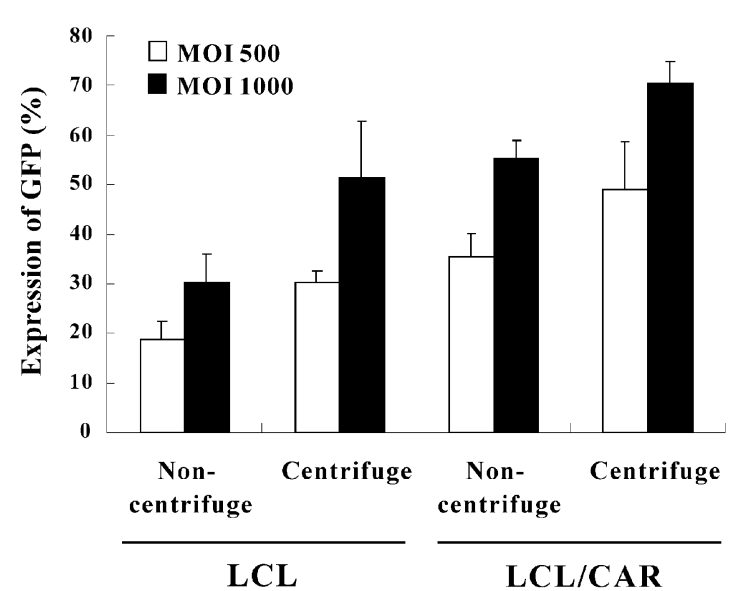

Fig. 4. Combined effect of the coxsackie adenovirus receptor (CAR) and the centrifugal force on the rAdVGFP transduction efficiency in the parental LCL and CAR-expressing LCL (LCL/ CAR) lines. Each cell line was transduced with rAdVGFP at an MOI of 500 (white bar) and an MOI of 1,000 (black bar). The green fluorescent protein (GFP) expression level was measured by flow cytometry. The results represent a mean $\pm S D$ of five experiments.

increased transduction rates of approximately $6 \%$ ( $\mathrm{SD} \pm 5.6$ and \pm 2.3 , respectively) when compared to other anionic polymers or liposomes. However, a combination of rAdV with other reagents had little effect on its transduction efficiencies. These results suggest that it might have little effect on rAdV binding to the cell surface and internalization.

Combined effect of CAR and centrifugal method on LCL cell lines Previously, the rates of rAdV infection in the LCL/ CAR lines were higher than in the LCL lines. An additional

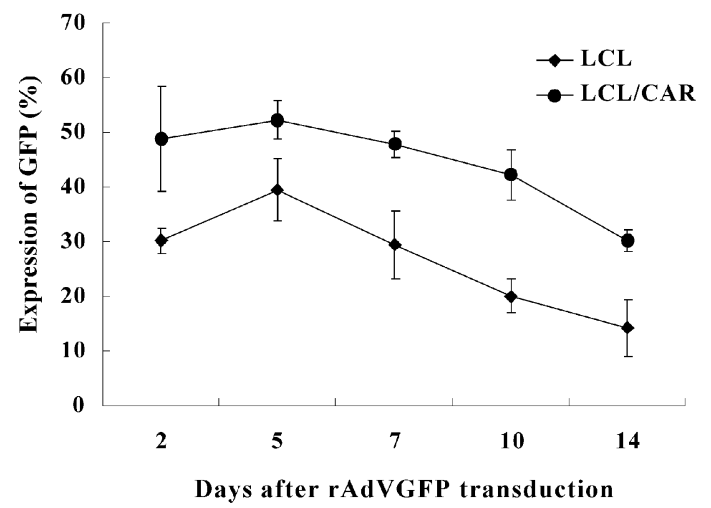

Fig. 5. Maintenance of the green fluorescent protein (GFP) expression level in parental LCL $(\diamond)$ and CAR-expressing LCL (LCL/CAR: -) lines. Each cell line was transduced with rAdVGFP at an MOI of 500, which was combined with centrifugal force. The GFP expression level was measured by flow cytometry. The results represent a mean $\pm \mathrm{SD}$ of three experiments.

centrifugal method enhanced its transduction efficiency to the LCL lines. Based on these results, this study examined the combined effect of the CAR expression and centrifugal force to increase the $\mathrm{rAdV}$ transduction efficiency in LCL lines (Fig. 4). At an MOI of 1,000, the rate of the rAdVGFP infection to the LCL and LCL/CAR lines was approximately $30 \pm 5.87 \%$ and $55 \pm 3.65 \%$, respectively, and the combined effect of the centrifugal force was $51 \pm 11.25 \%$ and $70 \pm$ $4.56 \%$, respectively. In order to confirm the stable expression of the transduced gene, the rAdVGFP-transduced LCL and LCL/CAR lines were incubated for a period of two wk (Fig. 5). The number of both of the GFP expressing cells increased slightly until $5 \mathrm{~d}$ after the rAdVGFP transduction, then decreased.

\section{Discussion}

One difficulty in studying the human antigen-specific CTL is that re-stimulating these effector cells often requires the use of autologous antigen-presenting cells (APCs). Hence, the original donor must make a repeated blood donation as a source of the APCs. Several groups demonstrated that autologous LCL lines might serve as an APC that is suitable for stimulating human immune cells (Curiel et al., 1993; Livingston et al., 1997). Therefore, the LCL lines that are induced to express the antigen of interest would be a useful and convenient source of autologous APCs. In this study, we report the efficient generation of foreign antigen-expressing LCL lines as a source of the APCs using a recombinant AdV vector.

A number of vectors were used to improve the transfection efficiencies of the LCL lines. Many groups have used the recombinant vaccinia virus (rVV) to express different viral antigens in the LCL lines (McFarland et al., 1993; van Baalen 
Table 1. Transduction efficiency of rAdVGFP on the LCL lines with the polycationic liposomes or anionic polymers*

\begin{tabular}{cccccccc}
\hline & Control & Lipofectamine & Suferfect & $\begin{array}{c}\text { Dextran } \\
\text { sulfate }\end{array}$ & Heparin & Polybrene & $\begin{array}{c}\text { Protamine } \\
\text { sulfate }\end{array}$ \\
\hline Non-centri $^{\text {Il }}$ & $12.7 \pm 3.5$ & $16.6 \pm 1.2$ & $16.4 \pm 2.3$ & $18.0 \pm 5.6$ & $18.3 \pm 2.3$ & $11.7 \pm 6.4$ & $14.7 \pm 3.3$ \\
Centri $^{\S}$ & $20.3 \pm 3.1$ & $19.3 \pm 2.6$ & $17.3 \pm 4.5$ & $22.7 \pm 6.5$ & $19.9 \pm 4.4$ & $12.5 \pm 1.3$ & $16.1 \pm 4.4$ \\
\hline
\end{tabular}

*The rAdVGFP were preincubated with each reagent at $2 \mu \mathrm{g} / \mathrm{ml}$ for $30 \mathrm{~min}$, and transduced to the LCL lines at an MOI of 100 . The green fluorescent protein (GFP) expression level was measured by flow cytometry. The results represent a mean \pm SD of three experiments.

"Non-centri: LCL lines were transduced with the pretreated-rAdVGFP for $4 \mathrm{~h}$.

${ }^{\S}$ Centri: LCL lines were centrifuged at $2,000 \times g$ for $2 \mathrm{~h}$ with pretreated-rAdVGFP, and subsequently incubated for $2 \mathrm{~h}$.

et al., 1993; Shankar et al., 1995). However, rVV may not be the ideal candidate for the antigen expression, because vaccinia itself is a potent immunogen, which makes it difficult to properly interpret the results of studies using the rVV in some vaccinia-immunized individuals. In addition, VV is lytic to cells. It is not possible to generate stable cell lines for examining antigen processing or presentation using rVV to express the individual viral proteins. Electroporation of the LCL lines has also been used in the study of gene therapy for B-cell malignancies. However, it is essential to use a large number (up to $10^{7}$ ) of cells to perform the electroporation. The efficiency of gene transfer was reported to be only 5 to $10 \%$ in the case of B cell chronic lymphocyte leukemia (Buschle et al., 1990). Curiel et al. described a high-efficiency gene transfer system to the LCL lines, based on the receptormediated endocytosis using an adenovirus as the DNA carrier (Curiel et al., 1992; Wagner et al., 1992; Curiel et al., 1994). Other methods for inducing the foreign gene expression in LCL lines, such as DEAE-dextran and lipofectin, were unsuccessful despite optimizing the processing conditions (Jerome et al., 1992). This study suggests that adenoviral transduction, as a technique for developing the expression of viral antigens, might have important advantages over other methods of antigen delivery to the LCL lines. In previous studies, although gene-modified LCL lines were generated by the transduction of recombinant retroviruses, it required a significant period of time (about 2 to $3 \mathrm{wk}$ ) to establish the stable transfectants expressing the foreign antigen (Sun et al., 2001). Although retroviral vectors have also been extensively used for gene delivery into lymphocytes, the experiments involving the retroviral transduction of lymphocytes are often limited by the difficulty in transducing the majority of the cells (Reimann et al., 1986), as well as the need for the cells to undergo mitosis for the viral integration and expression (Miller, 1992).

Although rAdV has many advantages in delivering the foreign gene in various cells, its efficiency in transducing the LCL lines is relative low due to the low CAR expression level that is needed for AdV to attach to the cell surface. Stockwin et al. reported that pre-treatment of the dendritic cells with a recombinant $\mathrm{AdV}$ encoding CAR significantly increased the uptake of the recombinant $\mathrm{AdV}$ by primary immature dendritic cells. Therefore, genetically-modified LCL lines were used to express CAR in order to enhance the transduction efficiency of rAdV. The transduction efficiency was as high as $60 \%$, but not up to $100 \%$ in the LCL/CAR lines. The parental LCL lines also increased at a high MOI when combined with centrifugation. This suggests that the AdV uptake needs a secondary cellular interaction involving the internalization of AdV into the host cells. Wang et al. reported that the AdV uptake is mediated by a secondary interaction between the RGD motifs on the AdV penton base protein loops and the integrins $\alpha_{v} \beta_{3}$ or $\alpha_{v} \beta_{5}$ (Wang et al., 1998). However, it takes a long time to establish the stable LCL lines expressing CAR. Although the effect of the centrifugal force is unclear, it might increase the chance of the virus particles to attach to their cellular receptor (Nishimura et al., 2001). Previous studies reported that the liposome-mixed AdV transduction had a higher efficiency in several cell types (Fasbender et al., 1997; Dietz and Vuk-Pavlovic, 1998). Based on these reports, $\mathrm{rAdV}$ was mixed with various polycationic liposomes or anionic polymers, followed by transduction to the LCL lines with subsequent centrifugation. However, no combined effect of centrifugation and polycationic liposomes or anionic polymers was observed.

In conclusion, these results suggest that the centrifugal force could be used to increase the transduction efficiency of rAdV to LCL lines. Although a future investigation will be needed to test whether or not the rAdV-transduced LCL lines can induce the antigen-specific CTL, it is believed that the LCL lines that are described in this paper could be a convenient source of autologous APCs for examining the human immune response.

Acknowledgments This work was supported by a Korea Research Foundation Grant (KRF-2001-005-F00017).

\section{References}

Bahnson, A. B., Dunigan, J. T., Baysal, B. E., Mohney, T., Atchison, R. W., Nimgaonkar, M. T., Ball, E. D. and Barranger, J. A. (1995) Centrifugal enhancement of retroviral mediated gene transfer. J. Virol. Methods 54, 131-143. 
Bergelson, J. M., Cunningham, J. A., Droguett, G., Kurt-Jones, E. A., Krithivas, A., Hong, J. S., Horwitz, M. S., Crowell, R. L. and Finberg, R. W. (1997) Isolation of a common receptor for Coxsackie B viruses and adenoviruses 2 and 5. Science 275, 1320-1323.

Bill, S. and Willie, M. (1977) Clonal transformation of adult human leukocytes by Epstein-Barr virus. J. Virol. 23, 503-508.

Buschle, M., Brenner, M. K., Chen, I. S., Drexler, H. G., Gignac, S. M. and Rooney C. M. (1990) Transfection and gene expression in normal and malignant primary B lymphocytes. $J$. Immunol. Methods 133, 77-85.

Byk, T., Haddada, H., Vainchenker, W. and Louache, F. (1998) Lipofectamine and related cationic lipids strongly improve adenoviral infection efficiency of primitive human hematopoietic cells. Hum. Gene Ther. 9, 2493-2502.

Clark, P. R., Stopeck, A. T., Brailey, J. L., Wang, Q., McArthur, J., Finer, M. H. and Hersh, E. M. (1999) Polycations and cationic lipids enhance adenovirus transduction and transgene expression in tumor cells. Cancer Gene Ther. 6, 437-446.

Curiel, D. T., Wagner, E., Cotten, M., Birnstiel, M. L., Agarwal, S., Li, C. M., Loechel, S. and Hu, P. C. (1992) High-efficiency gene transfer mediated by adenovirus coupled to DNApolylysine complexes. Hum. Gene Ther. 3, 147-154.

Curiel, T. J., Wong, J. T., Gorczyca, P. F., Schooley, R. T. and Walker, B. D. (1993) CD4+ human immunodeficiency virus type 1 (HIV-1) envelope-specific cytotoxic $\mathrm{T}$ lymphocytes derived from the peripheral blood cells of an HIV-1-infected individual. AIDS Res. Hum. Retroviruses 9, 61-68.

Curiel, T. J., Cook, D. R., Bogedain, C., Jilg, W., Harrison, G. S., Cotton, M., Curiel, D. T. and Wagner, E. (1994) Efficient foreign gene expression in Epstein-Barr virus-transformed human B-cells. Virology 198, 577-585.

DeMatteo, R. P., Chu, G., Ahn, M., Chang, E., Burke, C., Raper, S. E., Barker, C. F. and Markmann, J. F. (1997) Immunologic barriers to hepatic adenoviral gene therapy for transplantation. Transplantation 63, 315-319.

Dietz, A. B. and Vuk-Pavlovic, S. (1998) High efficiency adenovirus-mediated gene transfer to human dendritic cells. Blood 91, 392-398.

Dustin, M. L., Staunton, D. E. and Springer, T. A. (1988) Supergene families meet in the immune system. Immunol. Today 9, 213-215.

Eloit, M., Gilardi-Hebenstreit, P., Toma, B. and Perricaudet, M. (1990) Construction of a defective adenovirus vector expressing the pseudorabies virus glycoprotein gp50 and its use as a live vaccine. J. Gen. Virol. 71, 2425-2431.

Fasbender, A., Zabner, J., Zeiher, B. G. and Welsh, M. J. (1997) A low rate of cell proliferation and reduced DNA uptake limit cationic lipid-mediated gene transfer to primary cultures of ciliated human airway epithelia. Gene Ther. 4, 1173-1180.

George, M., Thomas, S., Hermann, L., Daphne, S. and Muriel, L. (1972) Epstein-Barr virus: Transformation, cytopathic changes, and viral antigens in squirrel monkey and marmoset leukocytes. Proc. Natl. Acad. Sci. USA 69, 383-387.

Ho, W. Z., Cherukuri, R., Ge, S. D., Cutilli, J. R., Song, L., Whitko, S. and Douglas, S. D. (1993) Centrifugal enhancement of human immunodeficiency virus type 1 infection and human cytomegalovirus gene expression in human primary monocyte/ macrophages in vitro. J. Leukoc. Biol. 53, 208-212.

Huang, S., Endo, R. I. and Nemerow, G. R. (1995) Upregulation of integrins alpha $\mathrm{v}$ beta 3 and alpha $\mathrm{v}$ beta 5 on human monocytes and $\mathrm{T}$ lymphocytes facilitates adenovirus-mediated gene delivery. J. Virol. 69, 2257-2263.

Hudson, J. B. (1988) Further studies on the mechanism of centrifugal enhancement of cytomegalovirus infectivity. J. Virol. Methods 19, 97-108.

Hureley, E. and Thorley-Lawson, D. (1988) B cell activation and the establishment of Epstein-Barr virus latency. J. Exp. Med. 168, 2059-2075.

Jerome, K. R., Bu, D. and Finn, O. J. (1992) Expression of tumor-associated epitopes on Epstein-Barr virus-immortalized B-cells and Burkitt's lymphomas transfected with epithelial mucin complementary DNA. Cancer Res. 52, 5985-5990.

Kim, D. J., Jang, H. J. Pyun, Y. R. and Kim, Y. S. (2002) Cloning, expression, and characterization of thermostable DNA polymerase from Thermoanaerobacter youseiensis. J. Biochem. Mol. Biol. 35, 320-329.

Lanuti, M., Kouri, C. E., Force, S., Chang, M., Amin, K., Xu, K., Blair, I., Kaiser, L. and Albelda, S. (1999) Use of protamine to augment adenovirus-mediated cancer gene therapy. Gene Ther. 6, $1600-1610$.

Lee, S. M., Lee, K. H., Kim, H. D., Lee, J. H., Lee, J. S. and Kim, J. (2001) Co-expression of MDRl and HLA-B7 Genes in a mammalian cell using a retrovirus. J. Biochem. Mol. Biol. 34, 176-181.

Leon, R. P., Hedlund, T., Meech, S. J., Li, S., Schaack, J., Hunger, S. P., Duke, R. C. and DeGregori, J. (1998) Adenoviralmediated gene transfer in lymphocytes. Proc. Natl. Acad. Sci. USA 95, 13159-13164.

Livingston, P. G., Kurane, I. and Ennis, F. A. (1997) Use of Epstein-Barr virus-transformed, autologous B-lymphoblastoid cells as antigen-presenting cells for establishment and maintenance of dengue virus-specific, human cytotoxic $\mathrm{T}$ lymphocyte clones. J. Virol. Methods 67, 77-84.

McFarland, E. J., Curiel, T. J., Schoen, D. J., Rosandich, M. E., Schooley, R. T. and Kuritzkes, D. R. (1993) Cytotoxic T lymphocyte lines specific for human immunodeficiency virus type $1 \mathrm{Gag}$ and reverse transcriptase derived from a vertically infected child. J. Infect. Dis. 167, 719-723.

Miller, A.D. (1992) Human gene therapy comes of age. Nature 357, 455-460.

Mueller, D. L., Jenkins, M. K. and Schwartz, R. H. (1989) Clonal expansion versus functional clonal inactivation: a costimulatory signaling pathway determines the outcome of $\mathrm{T}$ cell antigen receptor occupancy. Annu. Rev. Immunol. 7, 445-480.

Nishimura, N., Nishioka, Y., Shinohara, T., Ogawa, H., Yamamoto, S., Tani, K. and Sone, S. (2001) Novel centrifugal method for simple and highly efficient adenovirus-mediated green fluorescence protein gene transduction into human monocytederived dendritic cells. J. Immunol. Methods 253, 113-124.

Nissol, K. and Ponten, J. (1975) Classification and biological nature of established human hematopoietic cell lines. Int. J. Cancer 15, 321-341.

Ohlen, C., Bejarano, M. T., Gronberg, A., Torsteinsdottir, S., Franksson, L., Ljunggren, H. G., Klein, E., Klein, G. and Karre, K. (1989) Studies of sublines selected for loss of HLA expression from an EBV-transformed lymphoblastoid cell line. Changes in sensitivity to cytotoxic $\mathrm{T}$ cells activated by allostimulation and natural killer cells activated by IFN or IL-2. J. Immunol. 142, 3336-3341. 
Reimann, J., Heeg, K., Wagner, H., Keller, G. and Wagner, E. F. (1986) Introduction of a selectable gene into murine $\mathrm{T}$ lymphoblasts by a retroviral vector. J. Immunol. Methods $\mathbf{8 9}$, 93-101.

Richter, W., Eiermann, T. H. and Scherbaum, W. A. (1990) Effect of cytokines on proliferation of Epstein-Barr virus-transformed B lymphocytes. Hybridoma 9, 1-8.

Shankar, P., Fabry, J. and Lieberman, J. (1995) A simple method to selectively expand HIV-1 specific cytotoxic T lymphocytes in vitro. Immunol. Invest. 24, 489-497.

Stockwin, L. H., Matzow, T., Georgopoulos, N. T., Stanbridge, L. J., Jones, S. V., Martin I. G., Blair-Zajdel, M. E. and Blair, G. E. (2002) Engineered expression of the Coxsackie B and adenovirus receptor (CAR) in human dendritic cells enhances recombinant adenovirus-mediated gene transfer. J. Immunol. Methods 259, 205-215.

Sun, Q., Pollok, K. E., Burton, R. L., Dai, L. J., Britt, W.,
Emanuel, D. J. and Lucas, K. G. (2001) Simultaneous ex vivo expansion of cytomegalovirus and Epstein-Barr virus-specific cytotoxic $\mathrm{T}$ lymphocytes using B-lymphoblastoid cell lines expressing cytomegalovirus pp65. Blood 94, 3242-3450.

van Baalen, C. A., Klein, M. R., Geretti, A. M., Keet, R. I., Miedema, F., van Els, C. A. and Osterhaus, A. D. (1993) Selective in vitro expansion of HLA class I-restricted HIV-1 Gag-specific CD8+ T cells: cytotoxic T-lymphocyte epitopes and precursor frequencies. AIDS 7, 781-786.

Wagner, E., Zatloukal, K., Cotten, M., Kirlappos, H., Mechtler, K., Curiel, D. T. and Birnstiel, M. L. (1992) Coupling of adenovirus to transferrin-polylysine/DNA complexes greatly enhances receptor-mediated gene delivery and expression of transfected genes. Proc. Natl. Acad. Sci. USA 89, 6099-6103.

Wang, K., Huang, S., Kapoor-Munshi, A. and Nemerow, G. (1998) Adenovirus internalization and infection require dynamin. J. Virol. 72, 3455-3458. 